M. BALL, B. FOWLER, P. Li, L. A. JOYCE, F. Li, T. LiU, D. PALEY, Y. ZHONG, H. LI,* S. XIAO, ${ }^{*}$ F. NG, * M. L. STEIGERWALD, ${ }^{*}$ C. NUCKOLLS* (SHANGHAI NORMAL

UNIVERSITY, P. R. OF CHINA; COLUMBIA UNIVERSITY, NEW YORK AND MERCK

RESEARCH LABORATORIES, RAHWAY, USA)

Chiral Conjugated Corrals

J. Am. Chem. Soc. 2015, 137, 9982-9987.

\title{
Hand Specific Rings
}

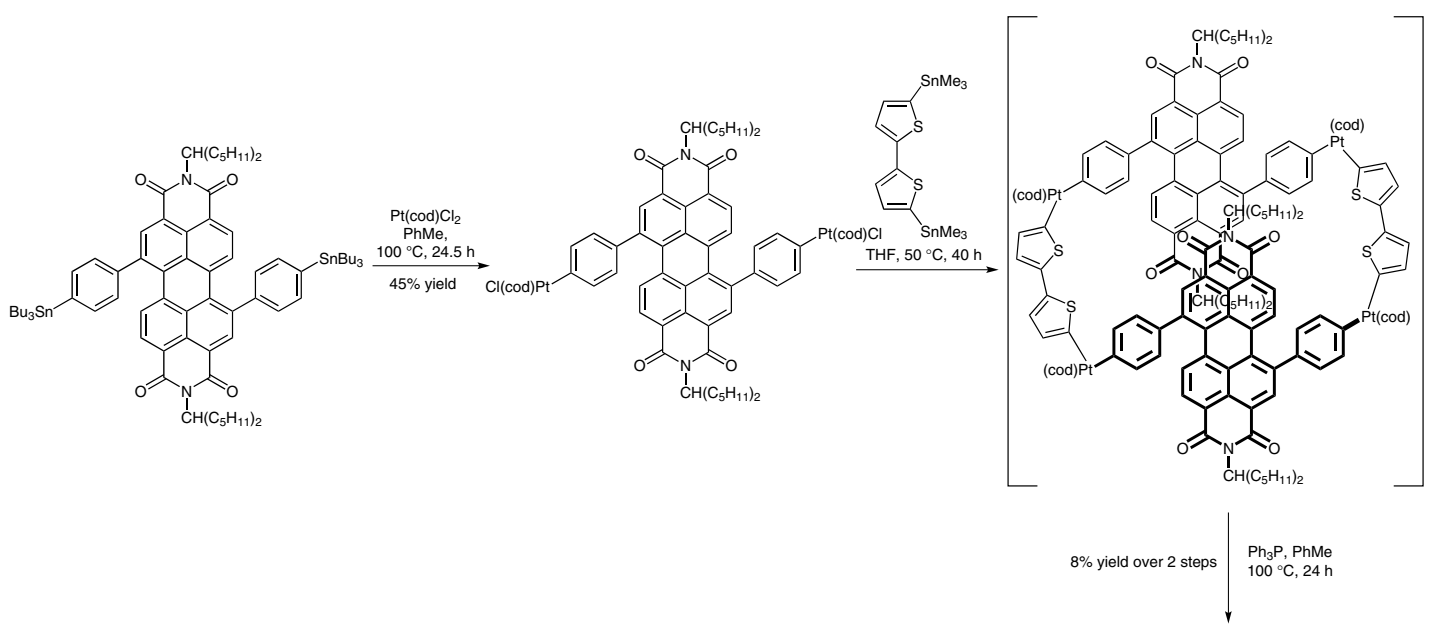

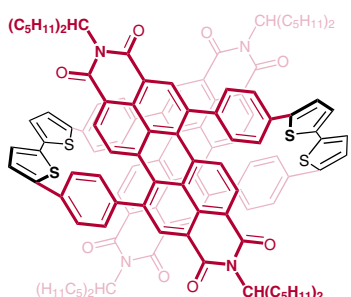

$(R, R)-\mathrm{CC} 1$

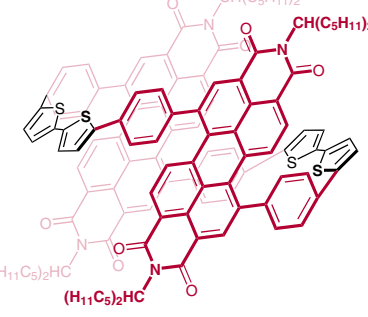

$(S, R)-\mathrm{CC} 1$

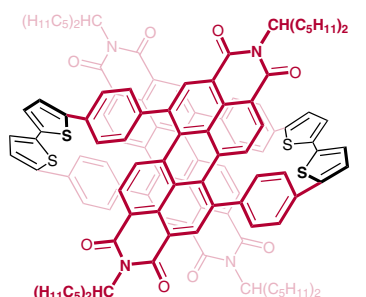

$(S, S)-\mathrm{CC} 1$
Significance: The first conjugated macrocycle containing alternating aromatic subunits -A-B-A$B-$ pattern was synthesized and studied in detail. Here, the diphenyl perlyene diimides serve as electron donors and the bithiophenes serve as electron acceptors. The new macrocycle has interesting structures and exists in dynamic equilibrium between the chiral and achiral forms. The unique electronic structure gives rise to an absorption spanning the entire visible light spectrum.

\section{Category}

Synthesis of

Materials and

Unnatural Products

\section{Key words}

conjugated macrocycles

bithiophenes

perylene diimide

interconversion

Synfact the wank
Comment: The three isomers (two enantiomers and one meso isomer) of macrocycle cc1 were isolated by HPLC on a chiral column. Enantiomers $(R, R)$-CC1 and $(S, S)$-CC1 interconvert at room temperature through the intermediacy of the meso isomer $(S, R)$-Cc1. Due to the branched undecyl side chains and the molecular dynamics, crystals of $\mathbf{C C 1}$ could not be obtained. DFT calculations showed that the frontier orbitals participate in intramolecular charge transfer. 